Max-Planck-Institut für demografische Forschung

Max Planck Institute for Demographic Research

Doberaner Strasse 114 - D-18057 Rostock · GERMANY

Tel +49 (0) 3812081 - 0; Fax +49 (0) 3812081 - 202;

http://www.demogr.mpg.de

MPIDR WORKING PAPER WP 2001-008

MARCH 2001

Intergenerational transfers: The ignored role of time

Sumon Kumar Bhaumik (bhaumik@demogr.mpg.de)

This working paper has been approved for release by: Alexia Fürnkranz-Prskawetz (fuernkranz@demogr.mpg.de),

Head of the Research Group on Population, Economy, and Environment.

(C) Copyright is held by the authors.

Working papers of the Max Planck Institute for Demographic Research receive only limited review. Views or opinions expressed in working papers are attributable to the authors and do not necessarily reflect those of the Institute. 


\title{
Intergenerational transfers: The ignored role of time*
}

\author{
Sumon Kumar Bhaumik**
}

\begin{abstract}
:
The literature on inter vivos and intergenerational transfers has largely focussed on the possible determinants of such transfers. Specifically, much of the empirical work has examined whether transfers are driven by altruistic relationship between "dynastic" households. However, the empirical literature has consistently overlooked the possibility that transfers may be driven by specific events in the recipients' lives like marriage, childbirth and illness. Further, it has not addressed the possibility that within a reasonably long time frame - say, one year - transfers may influence household income as much as household income influences the probability and magnitude of transfers. This paper addresses these lacunae in the existing literature. Using GSOEP data from the 1996 and 1997 surveys, it shows that demographic and other events determine transfers to a significant extent, and also that overlooking the possible endogeneity of income may lead to bias in the econometric estimations.
\end{abstract}

February 2001

\footnotetext{
Paper prepared using the German Socio-Economic Panel data available at the Max Planck Institute for Demographic Research. The author would like to thank Alexia Prskawetz, Ulf-Christian Ewert, Arnstein Aassave, Hans Peter Kohler and Jeffrey Nugent for their helpful comments, and Michaela Kreyenfeld for advice about the GSOEP data. The views expressed in this paper do not necessarily reflect the views of MPIDR, and the author remains responsible for all remaining errors. Post-doctoral research fellow, Max Planck Institute for Demographic Research, Doberaner Str. 114, 18057 Rostock, Germany. Tel: +49 381 2081198. Fax: +49 381 2081269. Email: Bhaumik@demogr.mpg.de.
} 


\section{Background}

The genesis for the exploration of motives underlying inter vivos transfers, of which intergenerational transfers are a special case, lay in the seminal papers of Barro (1974) and Becker (1974). The issue has survived the test of time, and has once again emerged as an important part of the economists' research agenda. There are primarily two reasons behind this surge of interest. First, an important implication of Barro's analysis is that any increase in social security benefits accruing to a member of the "dynastic" household would crowd out, perhaps even dollar for dollar, private intrahousehold transfers to that individual. Since the efficacy of publicly provided social security benefits, including non-monetary transfers like health care, is the focus of a major public policy debate, a better understanding of the motives underlying intergenerational transfers has become imperative.

Second, it has been argued that social security provisions that can provide cushion against a drop in consumption during old age may reduce "life cycle" savings, and hence reduce the volume of aggregate domestic savings (Lee, Mason and Miller, 2000). It is fairly obvious that, in the presence of appropriate social norms, private intergenerational or inter vivos transfers may also provide the aforementioned cushion, and thereby affect household and aggregate domestic savings. Many developing countries do not have publicly funded social security but have social norms that encourage private transfers. Further, industrialised countries are finding it increasingly difficult to sustain well funded social security systems, and hence private transfers may become increasingly important in these countries in the foreseeable future. Once again, therefore, it is important to understand the factors determining the probability of occurrence and the magnitude of private transfers.

The series of studies that were motivated by Cox (1987) largely focus on whether, and to what extent, inter vivos transfers are motivated by altruism. Cox himself found that the amounts of inter vivos transfers were positively related to the incomes of the recipients, an observation that contradicts the logic of altruism. Indeed, if parents and children are bound together by altruistic motives, then each of these two generations would be interested in preserving the consumption-welfare level of the other generation. This would imply that a transfer from one generation to the other would be induced by a fall in the income of the recipient generation. This logic was further extended by Altonji, Hayashi and Kotlikoff [henceforth AHK] (1992). They argued that, in the presence of altruism on the part of (say) a parent, if the parent's income goes down by one dollar, and simultaneously the child's income goes up by one dollar, then there would be one dollar less of transfers from the parent to the child. ${ }^{1}$

$1 \quad$ McGarry (2000) calls this the "derivatives" hypothesis, and argues that it would not hold "under reasonable assumptions about the formation of expectations about future income." Indeed, the 
The basic Cox-AHK line of argument has been extended, and tested in many different ways (Cox, 1990; Cox and Jimenez, 1992, 1993; Bhaumik and Nugent, 2000; McGarry, 2000). Further, alternative motives for inter vivos transfers like strategic motives have been brought into light (Bernheim, Shleifer and Summers, 1992; Cox and Stark, 1994; Pezzin and Schone, 2000). However, that altruism drives inter vivos transfers remains the null hypothesis for much of the empirical literature on intergenerational transfers, and, more generally, private transfers among members of dynastic households.

As such, the aforementioned null hypothesis is tested using a rule of thumb which can be highlighted using the paradigm of a simple probit or Tobit model in which a binary indicator of the occurrence of transfer or the amount of transfer itself is the dependent variable. ${ }^{2}$ Other things remaining the same, if the coefficient of income and/or the variable representing publicly provided benefits is negative and significant, it is argued that the data manifests the type of crowding out of private transfers, by other sources of income and consumables, that is consistent with the logic of altruism.

This paper argues that the stylised empirical methodology is seriously flawed on two different counts. First, income or publicly provided monetary and non-monetary benefits per se may not be the determinant of the private transfers. Such transfers are more likely to depend on events in the recipients' lives, viz., marriage, illness, and childbirth. Hence, at the very least, if a specification does not control for such events, the estimates would be vulnerable to omitted variable bias. Second, if the recall period of the data is as large as one year, it is reasonable to assume that transfers may affect income even as income may affect transfers. For example, if the parents of a young couple provide financial support to the latter such that the grandchildren can be sent to a day care centre, the female in the younger household may be able to join the labour force more effectively than otherwise, and this would certainly have a positive impact

linear relationship between income and private transfers implied by the "derivatives" hypothesis can be brought into question with a simple construction. If a fall in the income of (say) a child can be viewed as not only a decline in the current income, but also as a signal of the possibility that her future incomes might also be low, altruistic parents would have to transfer more to the child not only to counteract the latter's low income during the current period, but would also have to compensate her for lower income in the future periods. Hence, the strict dollar-for-dollar crowding-out implied by the "derivatives" hypothesis will not hold.

${ }_{2}$ The rationale for using a probit model with transfer (1) and no transfer ( 0$)$ as the binary dependent variable is obvious. The case for use of a Tobit model is more involved. It can be argued, for example, that a transfer is made by a donor if the act of making the transfer pushes her utility beyond some unobserved threshold. If $u$ denotes utility, and $u^{*}$ denotes the threshold level of utility, we can argue that a transfer is observed if $u>u^{*}$, and not otherwise. In other words, the distribution of transfers is censored, and hence the appropriate econometric formulation for its analysis is the Tobit model. 
on the latter household's income. If such simultaneity exists, and yet is not taken into consideration, once again the resultant empirical estimates may be biased.

The analysis presented in the subsequent sections of the paper goes on to show that "events" in the recipients' lives do matter, and have a significant impact on the probability of receiving a private transfer as well as the magnitude of the transfer. It also shows that income and transfers have a significant impact on each other, and therefore the appropriate method of estimation would be one using a simultaneous equation system. Section 2 of the paper expands on the rationale underlying the argument that the existing empirical methodology is flawed. Section 3 discusses the data used for the subsequent empirical analysis, namely, the German Socio-Economic Panel (GSOEP). It also provides a framework for the empirical analysis. The empirical results are presented and analysed in section 4 . Section 5 concludes, and suggests possible extensions of the analysis.

\section{The Lacunae in the Empirical Literature}

The literature on inter vivos (and hence intergenerational) transfers suffers from two shortcomings. First, it does not take into account the fact that households and individuals neither give nor receive transfers continually. ${ }^{3}$ Indeed, it is reasonable to assume that if households and individuals are altruistic, they would provide monetary support to others within the extended family or "dynastic" household in times of need, such that the consumption level of the recipient individual or household is sustained in the face of some crisis. For example, incidence of monetary transfers within a parent-child cohort may be high following marriages of the children, during periods in which the children suffer prolonged and serious illnesses, and when the children are out of work, in the absence of adequate unemployment compensation. Similarly, monetary transfers from the children to the parents are more likely to be observed during illnesses of the latter, and if the social security benefits of the aged parents are inadequate. In other words, it might be possible to observe transfers from a parent to a child during the latter's year of marriage, (say, $30^{\text {th }}$ ), year of major illness (say, $33^{\text {rd }}$ ), and year of temporary unemployment (say, $39^{\text {th }}$ ), and not during the other years of the adult child's lifetime.

The implications of this proposition are significant. As mentioned above, the usual "test" for altruism is to observe whether the probability of receiving a transfer and the magnitude of transfer vary inversely with the income of the recipient individual or

\footnotetext{
3 The transfers from children to elderly people in developing countries are often an exception to this "rule." In the absence of publicly funded social security provisions, and in the absence of life cycle savings, a large section of the elderly population in such countries may require continual transfers from their children for survival. In those contexts, the stylised empirical analysis may be more appropriate (Cox and Jimenez, 1992, 1993; Bhaumik and Nugent, 2000).
} 
household, and/or with the existence and extent of public support in the form of social security benefits. ${ }^{4}$ Let us assume that there are two households with the same income $x$, and that each household has a potential donor within its extended family, each donor's household income being $y$. Let us assume further that each of the potential recipients have the same non-income characteristics. Does this imply that during any time period either both or neither of these households would receive a transfer? It is obvious that this is very unlikely. For example, if one of the potential recipients fall prey to some illness, she would be more likely to receive transfers from her extended family. In other words, the (lack of) variation in $x, y$ and other explanatory variables would not be able to explain the fact that one of the potential recipients would actually receive a transfer while the other household would not. If, however, the specification includes an indicator of the health of the potential recipients, the asymmetry in the occurrence of transfer can be explained. Clearly, any examination of the motives underlying private transfers without controlling for income-reducing and expenditure- augmenting events in the lives of the recipient would not be meaningful. ${ }^{5}$

Further, this issue has implications for the savings behaviour of households. Let us assume that individuals and households save only for their old age consumption. If so, bequests can be explained only by the fact that death cannot be predicted as such, and hence a bequest is the difference between the expected old age consumption of an individual or couple and their actual consumption. In such an event, if individuals are able to fully annuitise their old age income-consumption by way of publicly funded pension and medical care, their propensity to save would decline. In other words, if a country experiences either the introduction of a new public pension system, or a reduction of the benefits of such a system, the implications for (aggregate) household savings may be significant. On the other hand, if bequests reflect, at least in part, the precautionary saving on the part of an individual or household to protect other "dynastic" households from income-consumption shocks, ${ }^{6}$ the impact of a change in the public pension and medical care regime on household savings would be much more muted.

\footnotetext{
$4 \quad$ If information is available about the donor's individual or household income, it may be used as a control variable because a low income household, for example, may not receive a transfer from another low income household within the "dynasty," even if the former household is in need for such a transfer per se. However, most surveys do not provide the relevant information about the donor, and hence studies in general are unable to control for this factor.

5 The only important piece of research acknowledging the limitation of the stylised methods of testing can be attributed to McGarry (1997).

6 In other words, a bequest may, at least in part, be a consequence of the fact that "events" in the lives of the "dynastic" households cannot be fully anticipated. It is evident that such a view of bequests is closely associated with the proposition that transfers are triggered by specific events in the lives of the recipients.
} 
There is one other aspect of inter vivos (and hence intergenerational) transfers that has not been adequately addressed in the existing literature, namely, the impact of the transfers on the earning potential of the recipients. It is obvious, for example, that people incur search costs when looking for jobs, and it would be reasonable to assume that the reservation wage of an individual depends on her ability to bear these costs. Indeed, policymakers have often argued that, therefore, it might not be advisable to provide a high level of unemployment benefit for an indefinitely long period of time. Hence, if, in the event of unemployment, an individual receives support in the form of private transfers, she is likely to be able to search for an appropriate job for a longer period of time, thereby increasing the probability of getting a higher paid job than she otherwise would. Similarly, as mentioned above, transfers may enable a member of the household to effectively join the labour force, and thereby augment both her own and the household's income. In other words, transfers can have an impact on an individual's or a household's income. ${ }^{7}$

One should note, however, that it is by no means obvious that the impact of private transfers on household income would necessarily be positive. For example, if a parent supports a child during a spell of unemployment, the child may spend much of the recall period searching for an appropriate job. In such an event, the child's income registered for the recall period might be lower than what it would have been in the absence of a transfer, which may have forced the child to reduce the search period. Similarly, following a childbirth, an event which would increase financial pressure on a household, if the parents of either of the spouses provide support in the form of private transfers, the female of the couple may stay back at home during the recall period to take care of the child. In that case, the impact of the private transfers on the household's income would be negative. In sum, the impact of private transfers on personal and household income is indeterminate.

Any empirical analysis of private inter household transfers should, therefore, involve a simultaneous equation system which treats income as an endogenously determined variable. However, the literature on inter vivos transfers treats income as an exogenously given explanatory variable influencing the probability and magnitude of transfers. An interesting deviation from this trend is the research of Pezzin and Schone (1998) which attempted to "predict jointly the combination of household membership [i.e., co-residence of parents and children], labour force participation, informal care and financial transfer provision resulting from parent and daughter

\footnotetext{
7 In light of the argument put forward by McGarry (2000), it can be argued that, therefore, if a household or individual receives a transfer in period $t$, such that this transfer has a positive impact on it's/his income, then the conditional probability that the household or individual would receive transfers in the future would decline. But in order to capture such dynamics one would have to use panel data models and such an analysis lies outside the scope of this paper.
} 
bargaining." However, the explanatory power of the Pezzin-Schone model has been limited by the absence of controls for transfer-inducing events and by the selectivity problem that arises because of the study's focus on female children.

\section{Data and Structure of Empirical Analysis}

The first round of survey for the GSOEP data was conducted in 1984 and it is "a longitudinal survey of private households and persons in the Federal Republic of Germany" (Haisken-Denew and Frick, 2000). Since then, each year the respondents are asked a core set of questions which include queries about demographic features of the households, income and social security benefits of the household members, their education, health and labour market performance, and expectations about the future. In 1984, the GSOEP survey covered 5,921 West German households. In 1990, households in the former German Democratic Republic were included in the survey. The data on households and individuals from the 1996 and 1997 surveys were combined to form the sample for the empirical analysis. The approximate number of households included in the survey during a year was about 6,800 , the number of individuals in each survey being about $13,000 .{ }^{8}$

The GSOEP data provides a wealth of information about the possible determinants of both transfers and income. Specifically, it provides information about the education, extent of labour market participation, and household wealth of individual respondents. It also provides demographic information like age, gender, and the number of children, as well as information about the extended families of individuals, namely, parents and siblings. Importantly, it provides information about events like marriage, childbirth, divorce and illness in the lives of the respondents, information that is crucial for the empirical exercise suggested above. Finally, the data provides information about monetary transfers.

However, while the surveys provide extensive information about several aspects of an individual's (and household's) "economic" life, it does not provide as much detail about the (monetary) transfers given and received by households. Specifically, the survey asks the respondents whether they transferred money to certain categories of people during the recall period, namely, parents/parents-in-law, children/ children-inlaw, separated/divorced spouse, other relatives, and unrelated persons. On the other hand, while each respondent is asked whether or not she received private transfers during the recall period, she is not required to identify the sources of such transfers.

\footnotetext{
$8 \quad$ Certain information like age and level of education attained were available in the 1996 data set. On the other hand, the data on income, transfers etc. were available from the 1997 data, the recall period being the previous year. Hence, the relevant information from the 1996 and 1997 data sets had to be combined to obtain information about all relevant variables.
} 
As a consequence, it is extremely difficult to match the donors with the corresponding recipients. 9

Ideally, an analysis of inter vivos transfers should bring together the information about both the donors and the recipients. But it is often not possible to obtain information about both donors and recipients, and in such events one has to focus either on the recipients alone (Bhaumik and Nugent, 2000), or on donors and recipients separately. The GSOEP data allows separate analysis of donors and recipients, and hence this study will opt for the latter.

The stylised practice in the existing literature is to examine individually the determinants of the probability of receiving (or giving) a transfer, and those for the magnitude of the transfer. As mentioned above, the former analysis involves the use of a probit or a logit model, with the dependent variable having a value of zero or one, for transfers received and not received respectively. Hence, if TRANSDUM represents the dummy dependent variable, the specification would be given by

$$
\text { TRANSDUM }=\gamma_{0}+\gamma_{1} \mathrm{INCOME}+\Gamma^{\prime} \mathrm{X}+\mathrm{e}
$$

when INCOME refers to the household income of the (potential) recipient, and $X$ corresponds to the values of the other variables determining the probability of a transfer. After taking into account the correlations between the explanatory variables, the specification for the GSOEP data included information on income and wealth of the recipients (and the households to whom they belonged), ${ }^{10}$ the geographical location of their home and workplace, ${ }^{11}$ demographic information, ${ }^{12}$ and various events. $^{13}$

\footnotetext{
$9 \quad$ For example, after an attempt was made to match donors with the corresponding recipients for the survey year 1997, only about 30 matches could be made unambiguously. One way to overcome this problem would be to pool matched observations over a number of years, so as to create a sample of a reasonable size. However, in order to undertake meaningful econometric exercises for such a sample, one would have to assume that the observations are independent of each other. However, if indeed transfers are precipitated by "events" in a recipient's life, the probability of receiving a transfer in period $t$ would be strongly correlated with the probability of receiving a transfer in an earlier period. For example, if a household receives a private transfer in period $t$ on account of childbirth, the absence of childbirth in the household in the previous $j$ periods would explain why the household did not receive such transfers between the $(t-j)^{\text {th }}$ period and the $t^{\text {th }}$ period.

10 These include the households' income net of taxes and private transfers (NETINC96), number of years of education (NOYEDU96), a dummy variable indicating whether or not potential recipients' households own the homes they live in (HOWNER96), and another dummy variable indicating whether or not the recipients' household has some form of liquid asset like a savings account (LIQAST96).

11 The economic disparities of West Germany and the former GDR have persisted over time. There is, therefore, reason to believe that the economic opportunities which determine the need for support from "dynastic" households differ between residents of and workers in these two parts of Germany. Hence, the specification controls for the impact of the location of home and work with two dummy variables indicating whether the respondents work in the former GDR (WRKGDR96) and whether they live in West Germany (LIVFDR96).
} 
The next step in the stylised literature is to explore the relationship between the magnitude of transfer and its possible determinants using a Tobit model. If the amount of transfers received by the households is given by TRANS96, the specification for the Tobit equation would be

$$
\text { TRANS96 }=\beta_{0}+\beta_{1} \text { INCOME }+B^{\prime} X+u
$$

It is generally argued that the data on transfers is vulnerable to a selection process, namely, if a household has a high probability of receiving a transfer then the magnitude of the transfer it receives is also likely to be high (Jurges, 1999). Hence, the Tobit model given by equation (2) is often estimated by the two-stage Heckman process which corrects the bias associated with the aforementioned problem of selection (Jurges, 1999; Bhaumik and Nugent, 2000).

\section{Results and Inference}

\subsection{Sample Selection and Descriptive Statistics}

Since this paper intends to focus on intergenerational transfers, it is necessary to construct the samples of potential donors and recipients such that the empirical results obtained from analyses of these samples have implications for private transfers across generations. Hence, people who are between 25 and 40 years of age are defined as potential recipients, while people who are more than 50 years of age are defined as potential donors. ${ }^{14}$ Moreover, since private inter household transfers aim to alleviate

12 Demographic information includes the age (AGE96) and gender (MALE96) of respondents, and also the number of dependent children in their households (NOCHLD96). Since the survey does not identify the source of private transfers, and yet it is reasonable to assume that much of the transfers originate from "dynastic" households of parents and siblings, two dummy variables are introduced to account for parents (PALIVE96) and siblings (SALIVE96) who are alive. Since the marital status of individuals was significantly correlated with some of the other explanatory variables, a dummy variable to indicate the marital status of an individual was omitted from the specification. However, coefficient estimates were also obtained with a dummy variable indicating marital status of an individual in the specification. The coefficient of the dummy variable itself was consistently negative and significant, as expected, but its introduction into the specification did not alter the qualitative analysis to any extent. Hence, in deference to the fact that the indicator of marriage is not orthogonal to some explanatory variables, it was left out of the specification.

13 The specification controls for five events in the lives of the respondents, namely, illness with the number of hospital visits as a proxy (NOHVST96), and marriage (MARAGE96), moving in with a partner (MOVEIN96), divorce (DIVORC96) and childbirth (CBIRTH96) during the recall period. $14 \quad$ In other words, this paper would analyse only downstream transfers. Trivially, this makes sense simply because, except for illness, "events" are likely to be important much for in the case of downstream transfers than for upstream transfers. The empirical rationale for it too is fairly simple, namely, the relative numbers of upstream and downstream transfers suggest that the latter is clearly the dominant form of transfers in Germany, at least as indicated by the 1996-97 GSOEP data. For example, of the 4169 individuals in the full data set of potential donors, only 67 reported transfers to parents or parents-in-law, while 390 reported transfers to children or children-in-law. It can be argued that people who are more than 50 years of age are more likely to make downstream rather than upstream transfers, often simply because they do not have live parents. However, even among the potential "recipients" in the 25-40 age group, only about 3 percent of the people reported making transfers to parents or parents- 
financial (or liquidity) pressures are more likely to occur among non-upper income households, and given that such transfers are more likely to have an impact on lower and middle income households, the choice of the recipients are restricted to households with values of NETINC96 less than 35,000 marks. Finally, since there is often a significant and positive correlation between the education and earnings potential of parents and children, the choice of donors too are restricted to households with values of NETINC96 less than 35,000 marks. The resultant samples for potential donors and recipients have 818 and 1765 observations respectively. ${ }^{15}$

The descriptive statistics for the potential donors (Table 1) throw up certain interesting patterns. It can be seen that people who make transfers to parents and parents-in-law $(P T R A N S D=1)$ are younger than those who provide transfers to children and children-in-law $(C T R A N S D=1)$, other relatives $(R T R A N S D=1)$ and non-relatives $(U T R A N S D=1)$, and that therefore a greater proportion of them are employed. ${ }^{16}$ On average, they have higher household income, but a smaller proportion of them has liquid assets. In other words, it can be hypothesised that while transfers to elderly parents are made out of current income, transfers to children and others are made out of the stock of savings. ${ }^{17}$ This implies that altruistic parents with foresight are likely to save in order to insure their children (and perhaps other members of "dynastic" households) against negative income or positive expenditure shocks. There is, at the very least, prima facie evidence about the possibility that the savings behaviour of rational individuals is likely to be influenced by their expectations about income and expenditure related shocks in the lives of their children and other people belonging to the "dynastic" households, the shocks themselves being precipitated by demographic and other events in the lives of the potential recipients.

Further, the individuals in the sample of potential donors had practically no demographic events - marriage, moving in with a partner, divorce and childbirth -in

in-law. Hence, it would be reasonable to argue that, given the data, an empirical analysis of upstream transfers would not be very meaningful.

$15 \quad$ The samples of donors and recipients for which the choice of observation was determined only by age, and not by income, have 2821 and 4169 observations respectively. The robustness of all results obtained from the age and income restricted samples were verified using the larger and less restricted sample. While there were differences in the magnitudes of the regression coefficients, and while in some cases not the same explanatory variables had significantly non-zero coefficients, the results obtained from the smaller samples were found to be, by and large, robust. The robustness was particularly evident for the "events" which were introduced in the specifications of the probit and Tobit models, as well as in the simultaneous equation system in which private transfers and household incomes were the two endogenous variables.

16 A very small proportion of the respondents seemed to have made transfers to spouses, and hence the characteristics of those individuals $(S T R A N S D=1)$ are not reported in Table 1 .

17 Interestingly, the people who do not make transfers to anyone during the recall period $(T R A N S D=0)$ have incomes that are comparable to incomes of those who make transfers to children, other relatives and non-relatives, but fewer individuals in the non-donor category have liquid assets compared to the aforementioned donors. 
their lives during the recall period. However, the non-donors reported significantly greater incidence of illness, on average, than the donors. Hence, illness as an "event" possibly influences not only the probability of receiving private transfers, but also the probability of making transfers.

It is not immediately obvious from the descriptive statistics whether making transfers to one category of potential recipients (for example, parents) crowds out the transfers made to other categories of potential recipients. ${ }^{18}$ Indeed, it can be seen that a significantly large proportion of those who make transfers to other relatives and nonrelatives also make transfers to children and children-in-law. A possible explanation for this apparent positive relationship is that those who make transfers to individuals who are not within the core of the "dynastic" families, have significant liquid assets and are, therefore, able to accommodate the needs of both children and those further away from the core of the "dynasty."

The descriptive statistics for the potential recipients (Table 3) indicate that, on average, the household income of the recipients, net of taxes and private transfers, are about 25 percent lower than that of non-recipients. In other words, it can be hypothesised that the coefficient of NETINC96 in the probit and Tobit estimations would be negative. More importantly, however, it is evident that recipients of private transfers (TRANSDUM =1) during the recall period experienced higher incidence of marriage, moving in with partners and childbirth than the non-recipients (TRANSDUM =0). This is consistent with our a priori hypothesis that "events" play a significant role in determining the probability of receiving transfers, and perhaps also the magnitude of the transfers.

Finally, while almost all of those who received transfers have at least one parent alive, the probability of having at least a live parent is 14 percentage points lower among non-recipients. This suggests that parents are perhaps the single most important source of transfers to those in the $25-40$ age group. This is also corroborated by the data on the potential donors. While 218 of these individuals reported making transfers to children and children-in-law during the recall period, many fewer individuals made transfers to the other categories of people.

\subsection{Regression Results: Impact of Events on Transfers}

A probit analysis (Table 2) indicates that the probability of making an intergenerational transfer to children and children-in-law is positively and significantly related to the educational attainment of a potential donor, whether or not

18 It is also not obvious as to whether people living and/or working in former GDR are more likely to make transfers than their West German counterparts. 
she has liquid assets like savings accounts and insurance policies, and the number of children she has. ${ }^{19}$ The positive relationship between the aforementioned probability and the number of children is easily explained. However, the significance of NOYEDU96 and LIQAST96 in determining this probability implies, once again, that savings for old age are meant not only to support old age consumption but also to provide support to "dynastic" households if such a need arises. Indeed, if the educational attainment of an individual is viewed as an indicator of her permanent income which, in turn, determines the quantum of savings, the relationship between savings for old age and precautionary motives for supporting "dynastic" households during a donor's old age comes sharply into focus.

The importance of this precautionary motive for savings, by way of savings for old age as indicated by the potential donors' permanent incomes, becomes even more evident when one takes into consideration the results of the Tobit analyses (Table 2). It can be seen that the magnitude of the transfers depend only on the educational attainment of the potential donors, education being a well accepted proxy for permanent income and hence lifetime savings.

The analyses involving the sample of potential recipients were undertaken using two different specifications. In the first specification, household income (NETINC96) was used as an explanatory variable, and hence the probit and Tobit models are as given by equations (2) and (3). However, since the magnitude of the household income itself does not indicate the financial condition of the household, the second specification replaced NETINC96 with per adult equivalent income (PAEINC96). ${ }^{20}$ Probit analyses involving these two specifications (Table 4) indicate that, as expected, the probability of receiving a transfer varies inversely with both the absolute and per adult equivalence household incomes, as well as with home ownership, and positively with the existence of at least one live parent. It is not obvious as to why this probability varies positively with the educational attainment of the potential recipients. One possible explanation is that parents who bear the cost associated with higher educational attainment are benevolent in general, and hence are also willing to provide private transfers more readily.

Importantly, however, the probit analyses indicate that demographic events like marriage, moving in with partners, and perhaps childbirth significantly increase the

\footnotetext{
19 Since the paper seeks to explore the determinants of intergenerational transfers, and given that more than 70 percent of the donors made transfers to children and children-in-law, it seemed reasonable to restrict the analysis to only transfers to the aforementioned younger generation. 20 The determination of adult equivalence for consumers of different age and gender is a complicated exercise in itself. Since the purpose of this exercise is to test the robustness of the qualitative results obtained from the Tobit analyses, it was simply assumed that a child's adult equivalence is 0.5 .
} 
probability of receiving transfers. The first criticism of the stylised empirical literature, explored in some detail in sections 1 and 2, is, therefore, vindicated. The importance of such events in determining the probability and magnitude of private transfers is further highlighted by the Tobit analyses (Tables 5 and 6). Indeed, the results of the Tobit estimations indicate that marriage, moving in with partners, and childbirth have a fairly significant impact on the magnitude of transfers received. ${ }^{21}$

The Tobit analyses also suggest that, as with the probability of receiving transfers, the magnitude of transfers varies negatively with absolute and per adult equivalent income, and positively with the existence of at least one live parent. Both the probit and Tobit estimates also indicate that the probability of receiving transfers, as also the magnitude of the transfers are lower for men. Further, the probability and the magnitude declines if a potential recipient lives in West Germany or works in former GDR. Since residence in West Germany implies access to more occupational (and perhaps financial) opportunities, the negative sign of the LIVFDR96 variable is not surprising. The similar sign of the WRKGDR96 variable can perhaps be explained by the possibility that if a person has a job in former GDR, he is possibly in a stronger financial position compared to a vast majority of his peers and "dynastic" households, and hence he is less likely to receive transfers.

\subsection{Simultaneity Between Income and Transfer}

The stylised probit and Tobit models indicate that there is a strong case in favour of using events as explanatory variables for transfers received. However, as explained in an earlier section, single equation models may not be appropriate for the analysis of transfers if the recall period is significantly large, namely, one year. Indeed, results obtained from the Hausman test suggests that NETINC96 is endogenously determined and hence cannot be treated as an exogenous variable in the Tobit equation that is used to estimate the relationship between the magnitude of transfers and its possible determinants. ${ }^{22}$ Hence, in order to account for the endogenous nature of NETINC96, a system of equations with NETINC96 and private transfers as endogenous variables have to be jointly estimated.

\footnotetext{
21 It is somewhat difficult to explain why the magnitude of transfers would vary inversely with the number of hospital visits. A possible explanation is that in the presence of publicly provided medical coverage and disability insurance the financial burden of illness is perhaps not as severe in Germany as in some other countries, and hence the coefficient of NOHVST96 is picking up effects of correlation between transfers and the number of hospital visits that cannot be explained by any causal relationship between hospital visits, financial burden and transfers.

22 The variable NETINC96 was regressed on all exogenous variables, and the residuals were saved as variable NETINC96R. Next, in the Tobit specification, NETINC96R was introduced as an additional explanatory variable. The coefficient of NETINC $96 R$ was significantly different from zero at the 1 percent level of significance. This suggested that the estimates of the Tobit model, which treated NETINC96 as an exogenous variable, are not consistent.
} 
In the earlier analyses, the unit of analysis was the individual. Since two people in the same household may have different probabilities of receiving transfers, depending on their gender, whether or not their parents and other "dynastic" individuals are alive, the (unaccounted for) differences in the financial abilities of the potential donors etc., this approach was meaningful. However, in order to analyse the determinants of transfers within a simultaneous equation framework, it is necessary to have similar units of measure for income and transfers. Since NETINC96 is a measure of household income, the measure of transfer used for the analysis should be gross private transfers received by the household, i.e., it is the sum of private transfers received by all individuals within the household (PVTTRN96).

Given that the household became the new unit of analysis, some other changes had to be introduced. Specifically, individual-specific variables like age and educational attainment were reconstructed as average of the age and numbers of years of education of the adults in the household. Further, the variable NOHVST96 was reconstituted to reflect the total number of hospital visits made by adult individuals in the households. At the same time, the dummy variables PALIVE96 and SALIVE96 were accorded value unity if any member of the household had a live parent and sibling respectively. Similarly, the dummy variable WRKGDR96 was given the value unity if any one of the adult household members worked in West Germany. Finally, the variable MALE96 was replaced by SPOUSE96, a dummy variable which indicated whether or not at least one pair of household adults were married.

The aforementioned system of equations, therefore, were given by

$$
\text { PVTTRN96 }=\phi_{0}+\phi_{1} \text { NETINC96 }^{\prime} \Phi^{\prime} \mathrm{X}_{1}+\mathrm{v}_{1}
$$

and

$$
\text { NETINC96 }=\sigma_{0}+\sigma_{1} \text { PVTTRN96 }+\Omega^{\prime} \mathrm{X}_{2}+\mathrm{v}_{2}
$$

where $X_{1}$ and $X_{2}$ comprise information about the exogenous variables. ${ }^{23}$ Joint estimation of this system of equations, one of which involves Tobit while the other

\footnotetext{
23 The explanatory variables for transfers in equation (3) are the same as those in equation (2) with one exception, namely, MALE96 was replaced by SPOUSE96. The explanatory variables for NETINC96 in equation (4) included PVTTRN96, average educational attainment of household members, the geographical location of the households' home and workplace, and dummy variables to capture existence of wealth and "dynastic" individuals like parents and siblings. Additionally, it included a dummy variable (ESTAT96) to indicate whether or not at least one adult member of the household was employed during the recall period, and an interaction between PALIVE96 and SALIVE96. This interaction term was introduced to capture the dynamics whereby the existence of an elderly parent may adversely affect effective labour force participation, but the coexistence of a sibling may ease the demand on the time of a household. Finally, the "events" were included. While marriage and moving in with a partner were expected to augment household income additively, and divorce impact household income negatively through the same arithmetic algorithm, childbirth was expected to
} 
involves OLS, is computationally costly. Hence, the estimation of the coefficients of equations (3) and (4) were undertaken by way of the two-stage procedure suggested in Maddala (1983). The estimates of the regression coefficients are presented in Table 7.

Since the focus of this analysis is on transfers, it would be reasonable to focus only on the signs and significance levels of the coefficients of the explanatory variables in the Tobit equation. Importantly, income continues to have a negative and significant coefficient, and existence of live parents and "events" - specifically, divorce and childbirth - continue to have the expected impact on the magnitude of private transfers. ${ }^{24}$ At the same time, control variables like NOCHLD96 and WRKGDR96 have experienced a reversal of their signs. However, the most striking difference between the results of the single and simultaneous equation frameworks is that in the former NOYEDU96 had a positive sign while in the latter the proxy for educational attainment has a negative sign. As mentioned above, it is possible to accord some plausible explanation to a positive sign of the NOYEDU96 variable. However, if education is a proxy for permanent income, it is reasonable to assume that higher levels of educational attainment would have a negative impact on the magnitude of private transfers. Indeed, irrespective of the magnitude of his current income, if a potential recipient is perceived to have a high permanent income, it is likely to be assumed that he has greater capacity to borrow against his future (higher) income stream, and hence he is likely to receive less support from "dynastic" households.

At the very least, the reversal of signs of coefficients of key explanatory variables in the transfer/Tobit equation suggests that is imperative to take into consideration the simultaneity between private transfers and income. Indeed, while it is reassuring to note that the signs of important determinants of private transfers like income and events, that are rooted in economic theory, have expected signs, and are hence robust, the importance of the exercise involving the simultaneous equation system is not diminished. Since in empirical analyses of economic phenomena robustness of estimates is important for meaningful policy discussions, ignoring the possibility that household income is endogenously determined might be a costly oversight.

\footnotetext{
have an impact on household income by way of a negative impact on the "time constraint" of the households.

$24 \quad$ Note that although "events" continue to matter, the relative importance of the events differ between the single equation Tobit model, and the simultaneous equation framework. In much of the earlier analysis, marriage and moving in with a partner were the triggers for flow of private transfers. However, in the simultaneous equation framework, childbirth and divorce have gained importance while marriage and moving in with a partner no longer have a significant impact on the magnitude of private transfers.
} 


\section{Concluding Remarks}

The literature on inter vivos and intergenerational transfers that has developed significantly since Cox's (1987) seminal contribution has two lacunae. First, it has ignored the role of specific events like marriage and childbirth in triggering private transfers. Second, it has ignored the possibility that household or individual income, an important explanatory variable for private transfers, may be endogenous, and that therefore a simultaneous equation framework may be more appropriate for analysing the determinants of private transfers. This paper has addressed both of these issues.

The analysis embodied in the paper has taken into consideration different specifications as well as different modelling paradigms - single equation probit and Tobit models, as well as a Tobit-OLS simultaneous equation system - and the signs and significance levels of important determinants of private transfers is fairly robust. Specifically, current household income unambiguously has a negative impact on receiving private transfers, while the aforementioned events, except for hospital visits, unambiguously have a positive impact on such transfers. At the same time, however, reversal in the sign of an important control variable like the educational attainment of the potential recipients, a proxy for their permanent incomes, indicates the necessity to check for endogeneity of household or personal income.

Apart from highlighting the lacunae in the econometric methodology used for empirical analyses of the determinants of private transfers, the paper also throws light on an issue that may have substantial relevance for macroeconomic analysis. It was proposed earlier in the paper that savings of individuals are aimed not only to support old age consumption but also to insure children and other members of "dynastic" families against negative income shocks and positive expenditure shocks. Such shocks are usually brought about by events such as illness, marriage, divorce and childbirth. The empirical analysis contained in the paper suggests that a simultaneous equation framework, which endogenises household income, is more appropriate for the analyses of private transfers. The simultaneous equation framework, in turn, suggests that divorce and childbirth as demographic events significantly determine the magnitude of private inter household transfers.

In most economically developed countries, divorce rate is increasing while the fertility rate has stabilised to a low level. In other words, for an individual, the probability of a childbirth in the lives of members of his "dynastic" household is low yet stable, while the probability of a divorce is rising over time. Hence, if the individual saves to insure the aforementioned household members against negative income and positive expenditure shocks, his aggregate savings would increase in response to the increasing probability of a divorce. The implication of such behaviour 
for aggregate household savings is obvious. However, the impact of divorce on the magnitude of transfers and hence, in turn, on the magnitude of the donor's savings, is not substantial. On the other hand, if developed countries have been witnessing postponement of childbirth, and if such behaviour is altered in the future such that two age cohorts decide to bear children within the same time period, there would be a steep increase in the incidence of childbirth. Given that childbirth in a recipient's household has a substantial impact on the magnitude of the private transfers it receives, such a phenomenon is likely to result in a steep increase in the magnitude of aggregate household savings.

The study has been limited by the fact that, given the nature of the questionnaire, it is not possible to match sufficient number of donors with recipients during a survey year. Hence, one simple yet important extension of this research endeavour is to examine the impact of "events" and the possible endogeneity of income with data that allows matching of donors and recipients. Further, this study has abstracted from an important form of inter vivos, and especially intergenerational, transfers, namely, nonmonetary transfers. Therefore, a second possible extension involves a fusion of this study with that by Pezzin and Schone (1998). Finally, it would be interesting to determine whether the intuition embodied in this paper holds true for private transfers in countries with public institutions and social norms that are significantly different from those in western developed countries. 


\section{References}

[1] Altonji, J. G., F. Hayashi and L. Kotlikoff, "Is the extended family altruistically linked? Direct Evidence Using Micro Data," American Economic Review, 82: 1177-1198, 1992.

[2] Barro, R. J., “Are government bonds net wealth?” Journal of Political Economy, 82: 1095-1117, 1974.

[3] Becker, G. S., "A theory of social interactions," Journal of Political Economy, 82: 1063-1093, 1974.

[4] Bernheim, B. D., A. Shleifer and L. Summers, "The strategic bequest motive," Journal of Political Economy, 93: 1045-1076, 1985.

[5] Bhaumik, S. K. and J. B. Nugent, "Wealth accumulation, fertility and transfers to elderly heads in Peru," (in). A. Mason and G. Tapinos (eds.) Sharing the Wealth, New York: Oxford University Press, 2000.

[6] Cox, D., "Motives for private income transfers," Journal of Political Economy, 95: 508-546, 1987.

[7] Cox, D., "Intergenerational transfers and liquidity constraints," Quarterly Journal of Economics, 105: 187-218, 1990.

[8] Cox, D. and E. Jimenez, "Social security and private transfers in developing countries: The case of Peru," World Bank Economic Review, 6: 155-169, 1992

[9] Cox, D. and E. Jimenez, "Private transfers and effectiveness of public income redistribution in the Philippines," Mimeo, Washington, D.C.: The World Bank, 1993.

[10] Cox, D. and O. Stark, "Intergenerational transfers and the demonstration effect," Mimeo, Boston College, Boston, Massachusetts, 1994.

[11] Haisken-DeNew, J. P. and J. R. Frick, Desktop companion to the German Socio-Economic Panel, version 3, Berlin: DIW, 2000.

[12] Jurges, H., "Parent-chid-transfers in Germany: A study of magnitudes and motivations," Zeitschrift fur Wirtschaft, 119(3): 422-453, 1999.

[13] Lee, R., A. Mason and R. Miller, "From transfers to individual responsibility: Implications for savings and capital accumulation in Taiwan and the United States," Mimeo, University of California at Berkeley, 2000.

[14] Maddala, G. S., Limited-dependent and qualitative variables in econometrics, Econometric Society Monographs, Cambridge University Press, 1983.

[15] McGarry, K., "Inter vivos transfers and intended bequests," NBER working paper 6345, 1997. 
[16] McGarry, K., "Testing parental altruism: Implications of a dynamic model," NBER working paper 7593, 2000.

[17] Pezzin, L. E and B. S. Schone, "Intergenerational household formation, female labor supply and informal care giving," Journal of Human Resources, 34(3): 475-503, 1998.

[18] Pezzin, L. E. and B. S. Schone, "Examining the motives for intergenerational transfers: A new test based on siblings' behavior," Mimeo, Johns Hopkins University School of Medicine, Baltimore, Maryland, 2000. 
Table 1

Descriptive Statistics (Older Generation)

\begin{tabular}{|c|c|c|c|c|c|}
\hline Variable & PTRANSD=1 & CTRANSD $=1$ & RTRANSD=1 & UTRANSD=1 & TRANSD $=0$ \\
\hline \multicolumn{6}{|c|}{ Income and wealth: } \\
\hline NETINC96 & $\begin{array}{r}18932.10 \\
(11715.09) \\
\end{array}$ & $\begin{array}{r}9055.57 \\
(11355.19) \\
\end{array}$ & $\begin{array}{r}6751.28 \\
(9771.35)\end{array}$ & $\begin{array}{r}9550.94 \\
(10516.62)\end{array}$ & $\begin{array}{r}8592.74 \\
(11076.82) \\
\end{array}$ \\
\hline PVTTRN96 & $\begin{array}{r}0 \\
(0.00)\end{array}$ & $\begin{array}{r}38.53 \\
(405.47)\end{array}$ & $\begin{array}{r}67.60 \\
(569.65)\end{array}$ & $\begin{array}{r}165.51 \\
(891.33)\end{array}$ & $\begin{array}{r}156.50 \\
(1851.79)\end{array}$ \\
\hline NOYEDU96 & $11.09 \quad(2.54)$ & $11.92 \quad(1.63)$ & $11.11(2.23)$ & $12.53 \quad(2.44)$ & $10.77(2.10)$ \\
\hline SIZOHH96 & $81.93(32.85)$ & $80.62(34.39)$ & $72.76(35.90)$ & $75.72(30.49)$ & 78.39 (31.44) \\
\hline HOWNER96 & $\begin{array}{ll}0.37 & (0.50) \\
\end{array}$ & $0.41 \quad(0.49)$ & $0.35 \quad(0.48)$ & $0.41 \quad(0.50)$ & $\begin{array}{ll}0.39 & (0.48)\end{array}$ \\
\hline LIQAST96 & $0.68 \quad(0.47)$ & $0.90 \quad(0.29)$ & $0.94 \quad(0.23)$ & $0.96(0.18)$ & $0.85 \quad(0.35)$ \\
\hline \multicolumn{6}{|c|}{ Geographical location: } \\
\hline WRKGDR96 & $\begin{array}{ll}0.06 & (0.25) \\
\end{array}$ & $0.03 \quad(0.18)$ & $\begin{array}{ll}0 \quad(0.00) \\
\end{array}$ & $0.03 \quad(0.18)$ & $\begin{array}{ll}0.03 \quad(0.17) \\
\end{array}$ \\
\hline LIVFDR96 & $0.37 \quad(0.50)$ & $0.67 \quad(0.46)$ & $0.67 \quad(0.47)$ & $0.48 \quad(0.50)$ & $0.73 \quad(0.44)$ \\
\hline \multicolumn{6}{|c|}{ Individual and household characteristics: } \\
\hline AGE96 & $57.43 \quad(4.83)$ & $66.97 \quad(8.44)$ & $70.23 \quad(9.08)$ & $65.72(8.14)$ & $66.26(8.59)$ \\
\hline MALE96 & $0.43 \quad(0.51)$ & $0.51 \quad(0.50)$ & $0.33 \quad(0.47)$ & $0.44 \quad(0.50)$ & $0.38 \quad(0.48)$ \\
\hline & $0.50 \quad(0.51)$ & $0.19 \quad(0.39)$ & $0.09 \quad(0.30)$ & $0.17 \quad(0.38)$ & $0.13 \quad(0.34)$ \\
\hline MST & $\begin{array}{ll}1.56 & (0.96) \\
\end{array}$ & $1.74(1.09)$ & $1.87 \quad(0.96)$ & $1.75(0.98)$ & $1.75 \quad(1.09)$ \\
\hline $\mathrm{NOC}$ & $1.56(1.15)$ & $2.20(1$. & $1.45(1$. & $1.00(1.06)$ & 1.79 (1.44) \\
\hline AEQUIV96 & $2.06 \quad(0.87)$ & $1.77 \quad(0.59)$ & $1.61(0.56)$ & $1.72(0.59)$ & $1.90 \quad(0.70)$ \\
\hline PALIVE96 & $\begin{array}{ll}0.68 & (0.47) \\
\end{array}$ & $0.11 \quad(0.31)$ & $\begin{array}{ll}0.08 \quad(0.28) \\
\end{array}$ & $\begin{array}{ll}0.10 & (0.30) \\
\end{array}$ & $\begin{array}{ll}0.13 \quad(0.33) \\
\end{array}$ \\
\hline SALIVE96 & $0.68 \quad(0.47)$ & $0.66(0.47)$ & $0.60 \quad(0.49)$ & $0.62(0.49)$ & $0.60 \quad(0.48)$ \\
\hline \multicolumn{6}{|l|}{ Events: } \\
\hline NOHVST96 & $0 \quad(0.00)$ & $0.27 \quad(0.97)$ & $0.21 \quad(0.50)$ & $0.31(0.76)$ & $0.91 \quad(1.57)$ \\
\hline MAR & \begin{tabular}{ll|}
0 & $(0.00)$ \\
\end{tabular} & $\begin{array}{ll}0 & (0.00) \\
\end{array}$ & $\begin{array}{ll}0 & (0.00) \\
\end{array}$ & $\begin{array}{ll}0 & (0.00) \\
\end{array}$ & $0.002 \quad(0.04)$ \\
\hline & $\begin{array}{ll}0 & (0.00)\end{array}$ & $0.004 \quad(0.06)$ & $0 \quad 0.0$ & $\begin{array}{ll}0 & (0.00)\end{array}$ & $0.002 \quad(0.05)$ \\
\hline DIV & $\begin{array}{ll}0 & (0.00) \\
\end{array}$ & $0 \quad(0.0$ & $0 \quad(0.0$ & $0 \quad(0.00)$ & $0 \quad(0.00)$ \\
\hline CBIRTH96 & $0.06 \quad(0.25)$ & $\begin{array}{ll}0 & (0.00) \\
\end{array}$ & $0.01 \quad(0.11)$ & $\begin{array}{ll}0 & (0.00) \\
\end{array}$ & $\begin{array}{ll}0 & (0.00) \\
\end{array}$ \\
\hline \multicolumn{6}{|c|}{ Incidence of transfer: } \\
\hline PTR & & $0.009 \quad(0.09)$ & $0.01 \quad(0.1$ & $0 \quad(0.00)$ & $0 \quad(0.00)$ \\
\hline CTR & $0.12(0.34)$ & & $0.22 \quad(0.42)$ & $0.31 \quad(0.47)$ & $\begin{array}{ll}0 & (0.00) \\
\end{array}$ \\
\hline STR & $\begin{array}{ll}0 & (0.00) \\
\end{array}$ & $0.004 \quad(0.06)$ & $0.01 \quad(0.11)$ & $\begin{array}{ll}0 & (0.00) \\
\end{array}$ & $\begin{array}{ll}0 & (0.00) \\
\end{array}$ \\
\hline RTR & $0.06 \quad(0.25)$ & $0.07 \quad(0.26)$ & & $0.31 \quad(0.47)$ & $\begin{array}{ll}0 & (0.00) \\
\end{array}$ \\
\hline UTRANSD & $\begin{array}{ll}0 & (0.00) \\
\end{array}$ & $0.04 \quad(0.19)$ & $0.14 \quad(0.35)$ & & $0 \quad(0.00)$ \\
\hline \multicolumn{6}{|c|}{ Amount of transfer: } \\
\hline PTRANS96 & $\begin{array}{r}2179.38 \\
(1812.44) \\
\end{array}$ & $\begin{array}{r}39.44 \\
(416.37)\end{array}$ & $\begin{array}{r}28.16 \\
(237.35)\end{array}$ & $\begin{array}{r}0 \\
(0.00)\end{array}$ & $\begin{array}{r}0 \\
(0.00) \\
\end{array}$ \\
\hline CTRA & $\begin{array}{r}537.50 \\
(1490.81) \\
\end{array}$ & $\begin{array}{r}7110.54 \\
(13383.97)\end{array}$ & $\begin{array}{r}560.56 \\
(1581.27) \\
\end{array}$ & $\begin{array}{r}834.46 \\
(1630.57) \\
\end{array}$ & $\begin{array}{r}0 \\
(0.00) \\
\end{array}$ \\
\hline STRANS96 & $\begin{array}{r}0 \\
(0.00)\end{array}$ & $\begin{array}{r}1.83 \\
(27.09)\end{array}$ & $\begin{array}{r}5.63 \\
(47.47)\end{array}$ & $\begin{array}{r}0 \\
(0.00)\end{array}$ & $\begin{array}{r}0 \\
(0.00)\end{array}$ \\
\hline RTRANS96 & $\begin{array}{r}93.75 \\
(375.00) \\
\end{array}$ & $\begin{array}{r}132.56 \\
(685.12) \\
\end{array}$ & $\begin{array}{r}3090.14 \\
(4652.48) \\
\end{array}$ & $\begin{array}{r}1779.31 \\
(4288.89) \\
\end{array}$ & $\begin{array}{r}0 \\
(0.00) \\
\end{array}$ \\
\hline UTRANS96 & $\begin{array}{r}0 \\
(0.00) \\
\end{array}$ & $\begin{array}{r}17.56 \\
(110.54) \\
\end{array}$ & $\begin{array}{r}157.74 \\
(491.83) \\
\end{array}$ & $\begin{array}{r}817.24 \\
(946.36) \\
\end{array}$ & $\begin{array}{r}0 \\
(0.00) \\
\end{array}$ \\
\hline \multicolumn{6}{|c|}{ Number of individuals: } \\
\hline $\mathrm{N}$ & 16 & 21 & 71 & 29 & 1465 \\
\hline
\end{tabular}


Table 2

Determinants of Probability and Magnitude of Transfers

Given to Children and Children-in-law

\begin{tabular}{|c|c|c|c|}
\hline Variables & Probit & Tobit & $\begin{array}{c}\text { Tobit (corrected } \\
\text { for selectivity bias) }\end{array}$ \\
\hline Constant & $-2.77 \quad(0.00)$ & $-3185.78(0.21)$ & $-3232.33 \quad(0.18)$ \\
\hline INVMILLS & & & $7110.14 \quad(0.00)$ \\
\hline \multicolumn{4}{|c|}{ Income and wealth: } \\
\hline NETINC96 & $1.31 \mathrm{E}-06 \quad(0.76)$ & $-0.001 \quad(0.93)$ & $0.02 \quad(0.35)$ \\
\hline NOYEDU96 & $0.08 \quad(0.00)$ & $180.71 \quad(0.07)$ & $186.82 \quad(0.05)$ \\
\hline HOWNER96 & $0.09 \quad(0.26)$ & $516.95(0.28)$ & $516.16 \quad(0.25)$ \\
\hline LIQAST96 & $0.25 \quad(0.04)$ & $508.28(0.44)$ & $503.10 \quad(0.41)$ \\
\hline \multicolumn{4}{|c|}{ Geographical location: } \\
\hline WRKFDR96 & $0.03 \quad(0.87)$ & $280.66(0.83)$ & $298.94 \quad(0.81)$ \\
\hline LIVGDR96 & $-0.08 \quad(0.36)$ & $-419.06(0.43)$ & $-410.11(0.41)$ \\
\hline \multicolumn{4}{|c|}{ Individual characteristics: } \\
\hline AGE96 & $0.001 \quad(0.83)$ & $8.08 \quad(0.79)$ & $17.15 \quad(0.55)$ \\
\hline MALE96 & $-0.009 \quad(0.91)$ & $71.27 \quad(0.87)$ & $81.92 \quad(0.85)$ \\
\hline NOCHLD96 & $0.14 \quad(0.00)$ & $190.98(0.23)$ & $196.72 \quad(0.19)$ \\
\hline \multicolumn{4}{|l|}{ Events: } \\
\hline NOHVST96 & $-0.01 \quad(0.65)$ & $-0.51 \quad(0.99)$ & $-2.47 \quad(0.98)$ \\
\hline \multicolumn{4}{|l|}{ Crowding out: } \\
\hline PTRANSD & $0.20 \quad(0.64)$ & $-276.20 \quad(0.91)$ & $-287.12(0.90)$ \\
\hline STRANSD & $-0.71 \quad(0.25)$ & $-1335.13(0.64)$ & $-1432.62 \quad(0.59)$ \\
\hline UTRANSD & $0.53 \quad(0.04)$ & $-227.39 \quad(0.86)$ & $-241.81 \quad(0.83)$ \\
\hline RTRANSD & $0.49 \quad(0.00)$ & $-294.12(0.86)$ & $-310.28 \quad(0.85)$ \\
\hline \multicolumn{4}{|l|}{ Statistic: } \\
\hline Log likelihood & -622.12 & -3620.55 & -3566.74 \\
\hline
\end{tabular}


Table 3

Descriptive Statistics (Younger Generation)

\begin{tabular}{|c|c|c|c|c|}
\hline & \multicolumn{2}{|c|}{ TRANSDUM $=0$} & \multicolumn{2}{|c|}{ TRANSDUM $=1$} \\
\hline Variable & Mean & Std. Dev. & Mean & Std. Dev. \\
\hline \multicolumn{5}{|c|}{ Dependent variable: } \\
\hline TRNS96 & 0 & 0 & 8534.08 & 5722.22 \\
\hline \multicolumn{5}{|c|}{ Income and wealth: } \\
\hline NETINC96 & 24032.41 & 8704.22 & 17949.98 & 9953.57 \\
\hline NOYEDU96 & 11.87 & 2.53 & 12.21 & 2.63 \\
\hline SIZOHH96 & 74.90 & 33.86 & 72.75 & 30.74 \\
\hline HOWNER96 & 0.19 & 0.39 & 0.10 & 0.31 \\
\hline LIQAST96 & 0.74 & 0.43 & 0.71 & 0.45 \\
\hline \multicolumn{5}{|c|}{ Geographical location: } \\
\hline WRKGDR96 & 0.17 & 0.37 & 0.06 & 0.24 \\
\hline LIVFDR96 & 0.27 & 0.44 & 0.15 & 0.36 \\
\hline \multicolumn{5}{|c|}{ Individual and household characteristics: } \\
\hline AGE96 & 31.83 & 4.18 & 31.13 & 3.92 \\
\hline MALE96 & 0.49 & 0.50 & 0.33 & 0.47 \\
\hline ESTAT96 & 0.67 & 0.46 & 0.31 & 0.46 \\
\hline MSTAT96 & 2.05 & 1.14 & 2.68 & 1.31 \\
\hline NOCHLD96 & 0.27 & 0.66 & 0.36 & 0.79 \\
\hline AEQUIV96 & 2.13 & 0.95 & 2.04 & 0.84 \\
\hline PALIVE96 & 0.84 & 0.35 & 0.98 & 0.12 \\
\hline SALIVE96 & 0.81 & 0.39 & 0.83 & 0.37 \\
\hline \multicolumn{5}{|l|}{ Events: } \\
\hline NOHVST96 & 0.15 & 0.45 & 0.12 & 0.37 \\
\hline MARAGE96 & 0.01 & 0.12 & 0.07 & 0.26 \\
\hline MOVEIN96 & 0.03 & 0.18 & 0.09 & 0.28 \\
\hline DIVORC96 & 0.01 & 0.10 & 0.01 & 0.12 \\
\hline CBIRTH96 & 0.04 & 0.20 & 0.09 & 0.28 \\
\hline \multicolumn{5}{|c|}{ Number of individuals: } \\
\hline $\mathrm{N}$ & & 752 & & 66 \\
\hline
\end{tabular}


Table 4

Determinants of Probability of Receiving Transfers

\begin{tabular}{|c|c|c|c|c|}
\hline \multirow{2}{*}{ Variable } & \multicolumn{2}{|c|}{ Specification 1} & \multicolumn{2}{|c|}{ Specification 2} \\
\hline & Coefficient & p-value & Coefficient & p-value \\
\hline & -1.46 & 0.07 & -1.67 & 0.04 \\
\hline \multicolumn{5}{|c|}{ Income and wealth: } \\
\hline NETINC96 & $-4.16 \mathrm{E}-05$ & 0.00 & & \\
\hline PAEINC96 & & & $-6.82 \mathrm{E}-05$ & 0.00 \\
\hline NOYEDU96 & 0.04 & 0.10 & 0.05 & 0.04 \\
\hline HOWNER96 & -0.30 & 0.18 & -0.45 & 0.05 \\
\hline LIQAST96 & 0.03 & 0.84 & 0.05 & 0.72 \\
\hline \multicolumn{5}{|c|}{ Geographical location: } \\
\hline WRKGDR96 & -0.43 & 0.08 & -0.45 & 0.07 \\
\hline LIVFDR96 & -0.32 & 0.08 & -0.36 & 0.05 \\
\hline \multicolumn{5}{|c|}{ Individual and household characteristics: } \\
\hline AGE96 & -0.01 & 0.51 & -0.01 & 0.29 \\
\hline MALE96 & -0.33 & 0.02 & -0.28 & 0.06 \\
\hline NOCHLD96 & 0.02 & 0.36 & 0.03 & 0.70 \\
\hline PALIVE96 & 1.08 & 0.00 & 1.21 & 0.00 \\
\hline SALIVE96 & -0.004 & 0.98 & 0.06 & 0.75 \\
\hline \multicolumn{5}{|l|}{ Events: } \\
\hline NOHVST96 & -0.42 & 0.05 & -0.30 & 0.14 \\
\hline MARAGE96 & 0.85 & 0.01 & 0.95 & 0.00 \\
\hline MOVEIN96 & 0.57 & 0.04 & 0.78 & 0.01 \\
\hline DIVORC96 & -0.15 & 0.81 & 0.17 & 0.79 \\
\hline CBIRTH96 & 0.63 & 0.03 & 0.34 & 0.25 \\
\hline \multicolumn{5}{|l|}{ Statistic: } \\
\hline Log likelihood & & -190.43 & & -186.03 \\
\hline
\end{tabular}


Table 5

Determinants of Magnitude of Transfer Received

\begin{tabular}{|c|c|c|c|c|}
\hline & \multicolumn{2}{|c|}{ Specification 1} & \multicolumn{2}{|c|}{ Specification 2} \\
\hline Variable & Coefficient & p-value & Coefficient & p-value \\
\hline Constant & -21549.39 & 0.06 & -24739.17 & 0.03 \\
\hline \multicolumn{5}{|c|}{ Income and wealth: } \\
\hline NETINC96 & -0.63 & 0.00 & & \\
\hline PAEINC96 & & & -1.01 & 0.00 \\
\hline NOYEDU96 & 586.09 & 0.13 & 758.83 & 0.05 \\
\hline HOWNER96 & -5154.64 & 0.11 & -7074.76 & 0.03 \\
\hline LIQAST96 & 943.67 & 0.67 & 1286.91 & 0.57 \\
\hline \multicolumn{5}{|c|}{ Geographical location: } \\
\hline WRKGDR96 & -7245.59 & 0.05 & -7404.90 & 0.04 \\
\hline LIVFDR96 & -4560.22 & 0.08 & -5068.72 & 0.05 \\
\hline \multicolumn{5}{|c|}{ Individual and household characteristics: } \\
\hline AGE96 & -129.78 & 0.62 & -243.07 & 0.35 \\
\hline MALE96 & -4480.18 & 0.03 & -3677.43 & 0.08 \\
\hline NOCHLD96 & 1460.98 & 0.29 & 709.51 & 0.60 \\
\hline PALIVE96 & 16020.27 & 0.00 & 17736.78 & 0.00 \\
\hline SALIVE96 & 2.39 & 0.99 & 1097.29 & 0.68 \\
\hline \multicolumn{5}{|l|}{ Events: } \\
\hline NOHVST96 & -6358.31 & 0.03 & -4484.77 & 0.12 \\
\hline MARAGE96 & 13073.06 & 0.00 & 14583.18 & 0.00 \\
\hline MOVEIN96 & 8447.992 & 0.03 & 11096.20 & 0.00 \\
\hline DIVORC96 & -1798.48 & 0.83 & 3040.47 & 0.73 \\
\hline CBIRTH96 & 8942.52 & 0.03 & 4434.28 & 0.28 \\
\hline \multicolumn{5}{|l|}{ Statistic: } \\
\hline Log likelihood & & -845.99 & & -842.47 \\
\hline
\end{tabular}


Table 6

Determinants of Magnitude of Transfer

(after correcting for selection bias)

\begin{tabular}{|c|c|c|c|c|}
\hline \multirow[b]{2}{*}{ Variable } & \multicolumn{2}{|c|}{ Specification 1} & \multicolumn{2}{|c|}{ Specification 2} \\
\hline & Coefficient & p-value & Coefficient & p-value \\
\hline Constant & -17593.31 & 0.04 & -21240.03 & 0.04 \\
\hline INVMILLS & 26910.02 & 0.00 & 27401.08 & 0.00 \\
\hline \multicolumn{5}{|c|}{ Income and wealth: } \\
\hline NETINC96 & -0.54 & 0.00 & & \\
\hline PAEINC96 & & & -0.80 & 0.00 \\
\hline NOYEDU96 & 290.95 & 0.25 & 337.87 & 0.21 \\
\hline HOWNER96 & -7800.36 & 0.00 & -8401.69 & 0.00 \\
\hline LIQAST96 & 1960.40 & 0.23 & 2570.55 & 0.13 \\
\hline \multicolumn{5}{|c|}{ Geographical location: } \\
\hline WRKGDR96 & -6985.99 & 0.00 & -6198.58 & 0.02 \\
\hline LIVFDR96 & -1485.36 & 0.44 & -1299.71 & 0.52 \\
\hline \multicolumn{5}{|c|}{ Individual and household characteristics: } \\
\hline AGE96 & 179.62 & 0.36 & 34.28 & 0.86 \\
\hline MALE96 & -1720.81 & 0.31 & -879.32 & 0.61 \\
\hline NOCHLD96 & 1062.68 & 0.21 & 788.27 & 0.37 \\
\hline PALIVE96 & 3371.45 & 0.43 & 6174.44 & 0.24 \\
\hline SALIVE96 & 360.13 & 0.83 & 1954.51 & 0.28 \\
\hline \multicolumn{5}{|l|}{ Events: } \\
\hline NOHVST96 & -5739.72 & 0.00 & -3460.74 & 0.08 \\
\hline MARAGE96 & 11369.89 & 0.00 & 12606.02 & 0.00 \\
\hline MOVEIN96 & 6278.45 & 0.00 & 8258.91 & 0.00 \\
\hline DIVORC96 & 561.29 & 0.91 & 5979.21 & 0.26 \\
\hline CBIRTH96 & 5839.04 & 0.01 & 1874.45 & 0.42 \\
\hline \multicolumn{5}{|l|}{ Statistic: } \\
\hline Log likelihood & & -654.13 & & -655.72 \\
\hline
\end{tabular}


Table 7

Simultaneous Determination of Magnitude of Transfer and Income

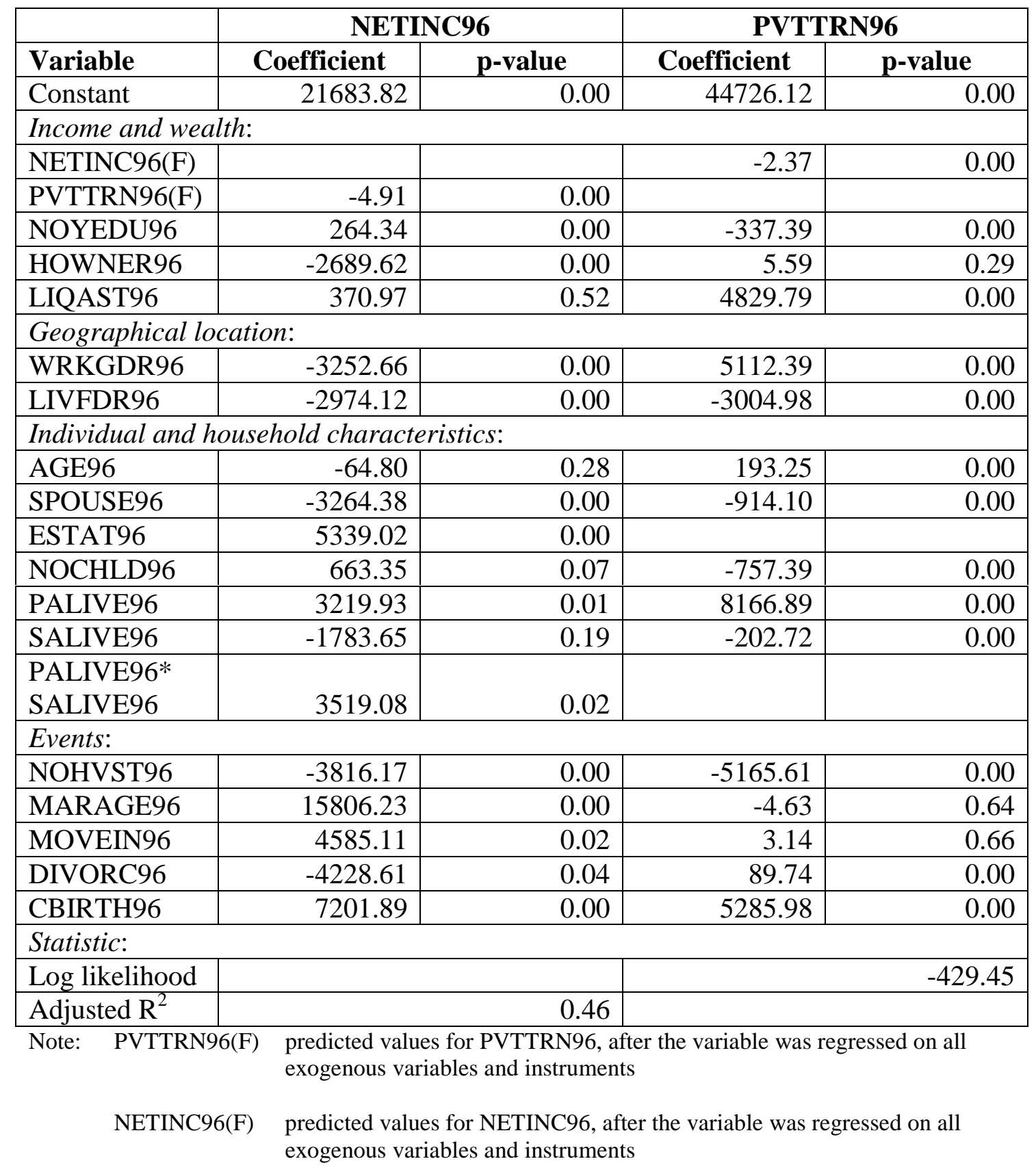

